\title{
Use of ceramic sanitaryware as an alternative for the development of new sustainable binders
}

\author{
REIG Lucía, a , BORRACHERO María V., ${ }^{2, b}$, MONZÓ José M. ${ }^{2, c}$, \\ SAVASTANO JR. Holmer ${ }^{3, \mathrm{~d}}$, TASHIMA Mauro M. ${ }^{4, \mathrm{e}}$ and PAYÁ Jordi ${ }^{2, \mathrm{f}}$ \\ ${ }^{1}$ Universitat Jaume I, Department of Mechanical and Building Engineering, Castelló de la Plana, \\ Spain
}

${ }^{2}$ Universitat Politècnica de València, Science and Technology Concrete Institute, Valencia, Spain

${ }^{3}$ University of São Paulo, Department of Biosystems Engineering, Pirassununga, SP, Brazil

${ }^{4}$ Universidade Estadual Paulista, Department of Civil Engineering, Ilha Solteira, SP, Brazil

aIreig@uji.es, 'bvorrachero@cst.upv.es, ${ }^{\mathrm{b}} \mathrm{jmmonzo@cst.upv.es,}{ }^{\mathrm{d}}$ holmersj@usp.br, emaumitta@gmail.com, fjjpaya@cst.upv.es

${ }^{*}$ corresponding author

Keywords: Ceramic Waste, Pozzolan, Alkali Activation, Mechanical Strength.

Abstract. Large amounts of ceramic sanitary-ware waste are generated in both the production process and construction and demolition practices. This waste contains amorphous phases that may react with the Portlandite that originates during Portland cement hydration or with an alkali solution, leading to a low $\mathrm{CO}_{2}$-binding material. This study investigated the pozzolanic activity of ceramic sanitary-ware waste, together with its potential to form new binders by alkali activation. For this purpose, raw material was characterized by X-ray diffraction, X-ray fluorescence, particle size distribution, thermogravimetry (TGA) and scanning electron microscopy (SEM). Percentages of ceramic waste of $15 \mathrm{wt} . \%$ and $25 \mathrm{wt} . \%$, to replace Portland cement, were used to assess the pozzolanic behavior of this material, and samples were cured at $20^{\circ} \mathrm{C}$ for different curing times. Alkali-activated samples, in which $\mathrm{Ca}(\mathrm{OH})_{2}$ was used as a source of calcium, and $\mathrm{NaOH}$ and sodium silicate solutions were utilized as activators, were cured for 7 days at $65^{\circ} \mathrm{C}$. The microstructural evolution of the developed binders was assessed in pastes by SEM and TGA analyses, and mortars were used to evaluate the compressive strength behavior. While some strength gain was observed due to pozzolanic activity, compressive strength values within the 14-36 $\mathrm{MPa}$ range were obtained in the alkali-activated mortars in accordance with the activator concentration and the percentage of $\mathrm{Ca}(\mathrm{OH})_{2}$ addition.

\section{Introduction}

According to the data provided by the ceramic industry, more than 300 million units of ceramic sanitary-ware products were produced worldwide in 2011. Ceramic waste originates not only during the production process (due to breakage or defective shapes), but also as construction and demolition waste. This waste is durable, hard and highly resistant to biological, chemical and physical degradation forces. Thus dumping it in landfills poses serious environmental problems, caused by dust pollution and the occupation of vast areas of land. The production of Portland cement, which is the most commonly used binder in concrete, is a high-energy process $(\approx 850 \mathrm{kcal}$ per $\mathrm{kg}$ of clinker) that generates large amounts of $\mathrm{CO}_{2}$ in the atmosphere (approximately $930 \mathrm{~kg}$ per tonne of PC produced) [1].

The scientific community, together with Portland cement and ceramic industries, has proposed interesting alternatives to re-use ceramic waste in the production of alternative construction materials. Among them, authors such as Halicka et al. [2] and Medina et al. [3] analyzed the use of 
ceramic sanitary-ware waste as a coarse aggregate in recycled concrete production. In the study by Puertas et al. [4], the suitability of different types of ceramic waste as raw material for Portland cement clinker production, and as pozzolanic admixtures, was proved. Ceramic waste, such as red clay bricks [5] or porcelain stoneware tiles [6], has also been successfully used to develop new binding systems by the alkali-activation process. All these alternatives help cut the amount of ceramic waste deposited, limit the mining of natural mineral aggregates and reduce associated negative environmental impacts.

The aim of this paper is to analyze the pozzolanic activity of ceramic sanitary-ware waste in Portland cement systems, and to investigate the potential of this waste to form new binders by alkali activation.

\section{Experimental procedure}

2.1. Materials. Ceramic sanitary-ware (CSW) pieces, such as basins and lavatory pans, were taken from dumps filled with construction waste. They were broken with a hammer and crushed in a jaw crusher BB200 (Retsch) to obtain a granular material with particles with a diameter of less than $4 \mathrm{~mm}$. The powder was then dry-milled in alumina media (Gabrielli Mill-2 ball mill) for 25 minutes ( 90 balls of alumina, $450 \mathrm{~g}$ of waste) and a powder with a mean particle size close to 23.9 $\mu \mathrm{m}, 90 \mathrm{vol. \%}$ (d90) less than $60.7 \mu \mathrm{m}$ and a d10 value of $1.7 \mu \mathrm{m}$ was obtained (Mastersizer 2000, Malvern Instruments).

Portland cement type CEM I 42,5R was used to assess the pozzolanic activity of the CSW residue. Replacing percentages of $15 \mathrm{wt} . \%$ and $25 \mathrm{wt} . \%$ of cement with CSW was done.

The alkali-activating solutions were prepared with sodium hydroxide pellets $(98 \%$ purity, Panreac), water and sodium silicate (Merck, $\mathrm{SiO} 2=28 \%, \mathrm{Na} 2 \mathrm{O}=8 \%, \mathrm{H} 2 \mathrm{O}=64 \%$ ). Calcium hydroxide (77\% purity) was used as a source of calcium.

2.2 Preparing CSW samples to assess pozzolanic activity. The pozzolanic activity of the ceramic residue was analyzed in pastes and mortars containing $15 \mathrm{wt} . \%$ and $25 \mathrm{wt} . \%$ of CSW to substitute Portland cement. A binder:sand:water ratio of 1:3:0.5 was used in the present study. Samples were cured in a temperature- and humidity-controlled chamber $\left(20^{\circ} \mathrm{C}\right.$ and $\left.95 \%\right)$ for 28 and 90 days.

2.3 Preparing alkali-activated CSW samples. Alkali-activated CSW pastes and mortars were prepared with a water to binder ratio of 0.40 , where the binder was composed of ceramic waste and was partially replaced with $\mathrm{Ca}(\mathrm{OH})_{2}$. The mix proportions investigated in this research are summarized in Table 1 . The $\mathrm{Na}^{+}$concentration, provided by $\mathrm{NaOH}$ pellets and the sodium silicate solution, ranged from 2.5 to $12.5 \mathrm{~mol} / \mathrm{kg}$, and four different $\mathrm{SiO}_{2}$ concentrations were used (1.82 to $7.28 \mathrm{~mol} / \mathrm{kg})$.

The $\mathrm{SiO}_{2} / \mathrm{Na}_{2} \mathrm{O}$ mass ratio, together with the modulus of sodium $\left(\mathrm{M}_{\mathrm{Na}}\right)$ and the modulus of calcium $\left(\mathrm{M}_{\mathrm{Ca}}\right)$, were proved to greatly influence the workability and setting time of alkali-activated porcelain stoneware mortars in [6]. $\mathrm{M}_{\mathrm{Na}}$ is the ratio between the number of moles of $\mathrm{Na}^{+}$in the activating solution and the $\mathrm{SiO}_{2}$ and $\mathrm{Al}_{2} \mathrm{O}_{3}$ contents in the raw material $(\mathrm{CSW}) . \mathrm{M}_{\mathrm{Ca}}$ showed the correlation between the moles of $\mathrm{Ca}^{2+}$ (supplied as $\mathrm{Ca}(\mathrm{OH})_{2}$ ) and the moles of $\mathrm{Na}^{+}$in the activating solution. All the samples developed in the present study were mixed with a constant $\mathrm{M}_{\mathrm{Ca}}$, equal to 0.156. Then the amount of $\mathrm{Ca}(\mathrm{OH})_{2}$, to substitute ceramic waste, varied from $1.5 \mathrm{wt} . \%$ to $7.5 \mathrm{wt} . \%$ for the samples with 2.5 and $12.5 \mathrm{~mol} / \mathrm{kg}$ of sodium, respectively.

The alkaline-activating solutions were prepared by dissolving $\mathrm{NaOH}$ pellets in water and adding the required amount of sodium silicate solution. The ceramic residue and the $\mathrm{Ca}(\mathrm{OH})_{2}$ powder were dry-blended, and were then mixed with the alkaline solution for 4 min to obtain pastes. A binder to sand ratio of 1:3 was used to obtain mortars (siliceous sand), which were placed into a mold and vibrated for 4 min immediately after the mixing process. Pastes and mortars were stored at $65^{\circ} \mathrm{C}$ and at $90-95 \%$ relative humidity for 3 and 7 days. 
Table 1 - The components and ratios of the alkali-activation solutions

\begin{tabular}{|c|c|c|c|c|}
\hline $\begin{array}{c}\mathrm{Na}^{+} \\
\text {mol.kg }\end{array}$ & $\begin{array}{c}\mathrm{SiO}_{2} \\
\text { mol.kg-1 }\end{array}$ & $\begin{array}{c}\mathrm{Ca}(\mathrm{OH})_{2} \\
\text { wt.\% }\end{array}$ & $\begin{array}{l}\mathrm{SiO}_{2} / \mathrm{Na}_{2} \mathrm{O} \\
\text { mass ratio }\end{array}$ & $\begin{array}{c}\mathrm{M}_{\mathrm{Na}} \\
\text { molar ratio }\end{array}$ \\
\hline 2.5 & \multirow{4}{*}{1.82} & 1.5 & 1.41 & 0.076 \\
\hline 5.0 & & 3.0 & 0.71 & 0.155 \\
\hline 7.5 & & 4.5 & 0.47 & 0.236 \\
\hline 10.0 & & 6.0 & 0.35 & 0.320 \\
\hline 2.5 & \multirow{4}{*}{3.64} & 1.5 & 2.82 & 0.076 \\
\hline 5.0 & & 3.0 & 1.41 & 0.155 \\
\hline 7.5 & & 4.5 & 0.94 & 0.236 \\
\hline 10.0 & & 6.0 & 0.71 & 0.320 \\
\hline 3.0 & \multirow{4}{*}{5.46} & 1.8 & 3.53 & 0.092 \\
\hline 5.0 & & 3.0 & 2.12 & 0.155 \\
\hline 7.5 & & 4.5 & 1.41 & 0.236 \\
\hline 10.0 & & 6.0 & 1.06 & 0.320 \\
\hline 5.0 & \multirow{4}{*}{7.28} & 3.0 & 2.82 & 0.155 \\
\hline 7.5 & & 4.5 & 1.88 & 0.236 \\
\hline 10.0 & & 6.0 & 1.41 & 0.320 \\
\hline 12.5 & & 7.5 & 1.13 & 0.407 \\
\hline
\end{tabular}

2.4. Characterization. The CSW raw material was physico-chemically characterized. The chemical composition of the ceramic powder was determined by X-ray Fluorescence in a Philips Magix Pro spectrometer, fitted with a rhodium tube and a beryllium window. Crystalline phases were identified by X-ray diffraction in a Brucker diffractometer AXS D8 Advance, with $\mathrm{Cu} \mathrm{K} \alpha$ radiation, $40 \mathrm{kV}$ and $20 \mathrm{~mA}, 2 \theta$ from $5^{\circ}$ to $70^{\circ}$. The morphology of the grounded CSW particles was examined in a SEM-EDX JEOL JSM6300 electronic microscope. The weight loss of the CSW was investigated in an air atmosphere in a Mettler-Toledo TGA850 thermobalance using alumina crucibles at a heating rate of $20^{\circ} \mathrm{C}$ min- 1 , from $35^{\circ} \mathrm{C}$ to $1000^{\circ} \mathrm{C}$.

Mortar samples were prepared to assess the compressive strength evolution of the newly developed binders following UNE EN 196-1. The compressive strength results of the mortars with pozzolanic additions were presented in terms of the strength activity index (SAI) and strength gain (SG). While the SAI correlates the compressive strength of the mortars containing ceramic waste with that of the control, SG is calculated according to Eq. 1.

$S G(\%)=\frac{\left|C s_{P O Z}-\left(C s_{\text {control }} \cdot \operatorname{Cem} \%\right)\right|}{C s_{\text {control }} \cdot C e m \%} * 100$

where:

$\mathrm{Cs}_{\mathrm{poz}}=$ compressive strength of the mortar with CSW;

$\mathrm{Cs}_{\text {control }}=$ compressive strength of the control mortar;

$\mathrm{Cem} \%=$ percentage of cement in the mortar containing CSW (per unit).

Pastes of selected mortars were characterized by SEM and TGA. The weight loss of the paste samples was analyzed by thermogravimetry in an $\mathrm{N}_{2}$ atmosphere using sealed pin-holed aluminum crucibles at a heating rate of $10^{\circ} \mathrm{C}$ min- 1 from $35^{\circ} \mathrm{C}$ to $600^{\circ} \mathrm{C}$.

\section{Results}

3.1. CSW characterization. As observed in Table 2, the ceramic sanitary-ware waste (CSW) is composed mainly of $\mathrm{SiO} 2$ and $\mathrm{A} 12 \mathrm{O} 3$ (89.6 wt.\%). The thermogravimetric analyses of the CSW denoted a minimum total weight loss $\left(0.10 \mathrm{wt} \%\right.$ ), with no significant peaks within the $35-1000^{\circ} \mathrm{C}$ range. 
Table 2 - Chemical Composition of CSW.

\begin{tabular}{ccccccccc}
\hline & $\mathrm{Al}_{2} \mathrm{O}_{3}$ & $\mathrm{SiO}_{2}$ & $\mathrm{CaO}$ & $\mathrm{Fe}_{2} \mathrm{O}_{3}$ & $\mathrm{~K}_{2} \mathrm{O}$ & $\mathrm{P}_{2} \mathrm{O}_{5}$ & Others & LOI \\
\hline $\mathrm{CSW}$ & 23.6 & 66.0 & 1.2 & 1.3 & 2.9 & 0.5 & 1.4 & 0.3 \\
\hline
\end{tabular}

The data in Fig. 1 show that quartz $\left(\mathrm{Q}, \mathrm{SiO}_{2}\right)$ and mullite $\left(\mathrm{M}, \mathrm{Al}_{6} \mathrm{Si}_{2} \mathrm{O}_{13}\right)$ are the major crystalline phases in the ceramic waste, and that potassium feldspar microcline $\left(\mathrm{m}, \mathrm{KAlSi}_{3} \mathrm{O}_{8}\right)$ was present as a minor constituent. The deviation from the baseline within the range of 15-30 20 degrees denotes a considerable amount of amorphous phases in the waste material.

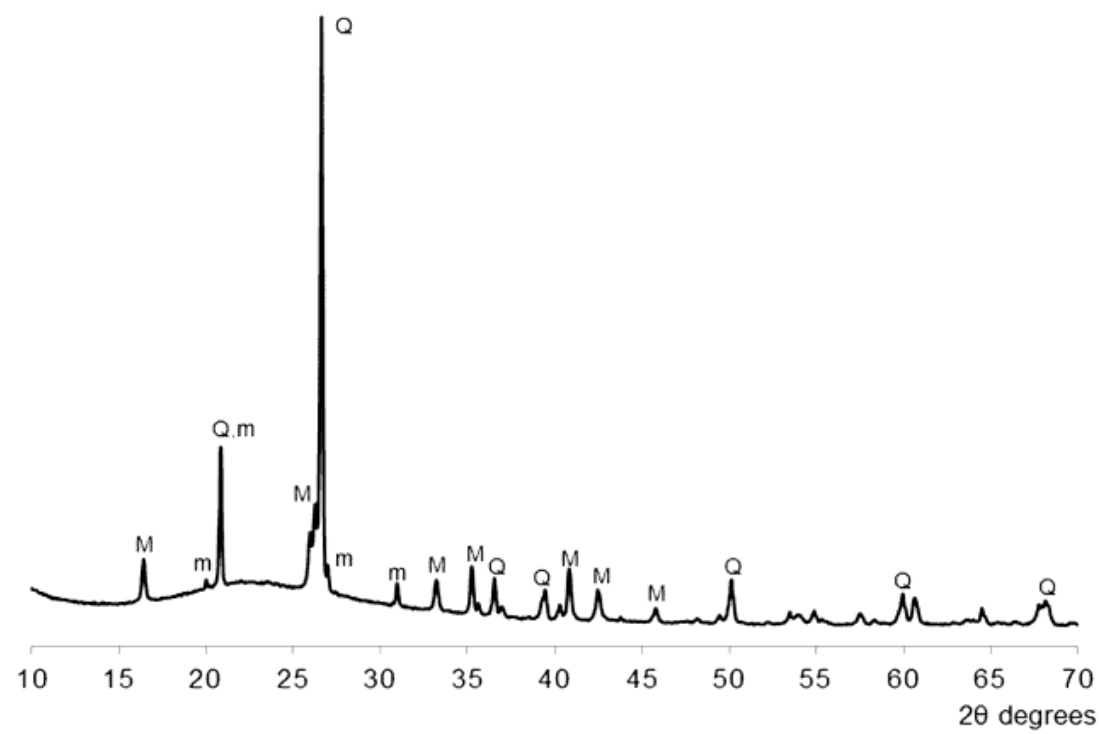

Fig. 1 -X-Ray diffraction pattern of ground CSW. Q: Quartz; M: Mullite; m: Microcline.

As observed in Fig. 2, dense irregular particles, with a wide particle size distribution, resulted from the milling process.

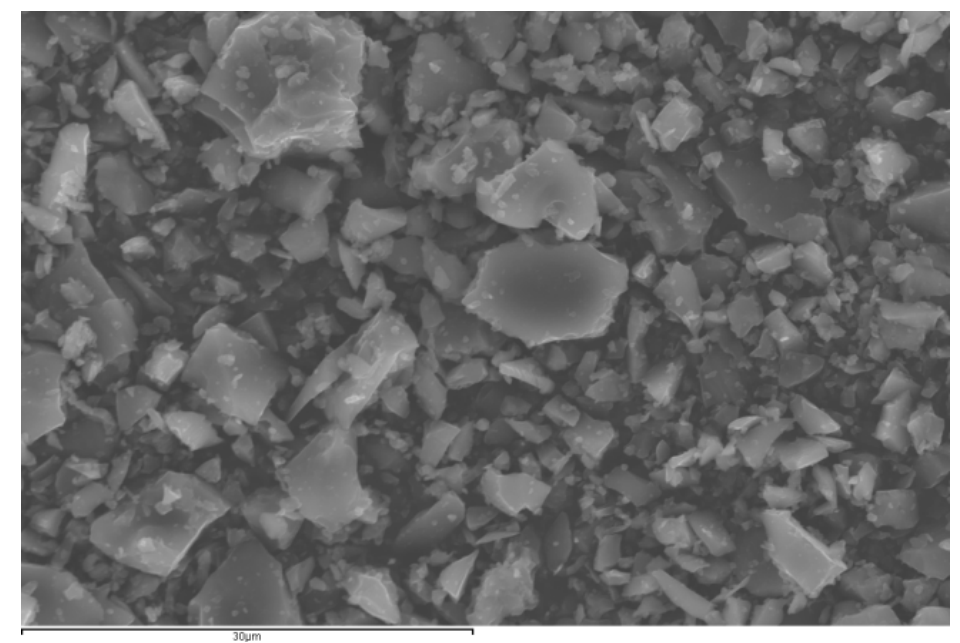

Fig. 2 - SEM micrograph of ground CSW.

\subsection{Mechanical properties of the developed mortars.}

3.2.1. Compressive strength of pozzolanic mortars. The compressive strength values of the control mortar (no CSW) and that with 15 and $25 \mathrm{wt} \% \mathrm{CSW}$, cured at $20^{\circ} \mathrm{C}$ for 28 and 90 days are plotted in Fig. 3. Although the mortars containing ceramic waste presented lower compressive strength values than that of the control mortar, the difference was notably smaller after 90 curing days. Thus, strength diminished by $5.8 \%$ and $18.6 \%$ in the samples containing 15 wt.\% and 25 wt. $\%$ CSW cured for 28 days, and these values lowered to $2.4 \%$ and $11.9 \%$ in the mortars cured for 90 days. This positive evolution is attributed to the pozzolanic activity of the ceramic waste. 


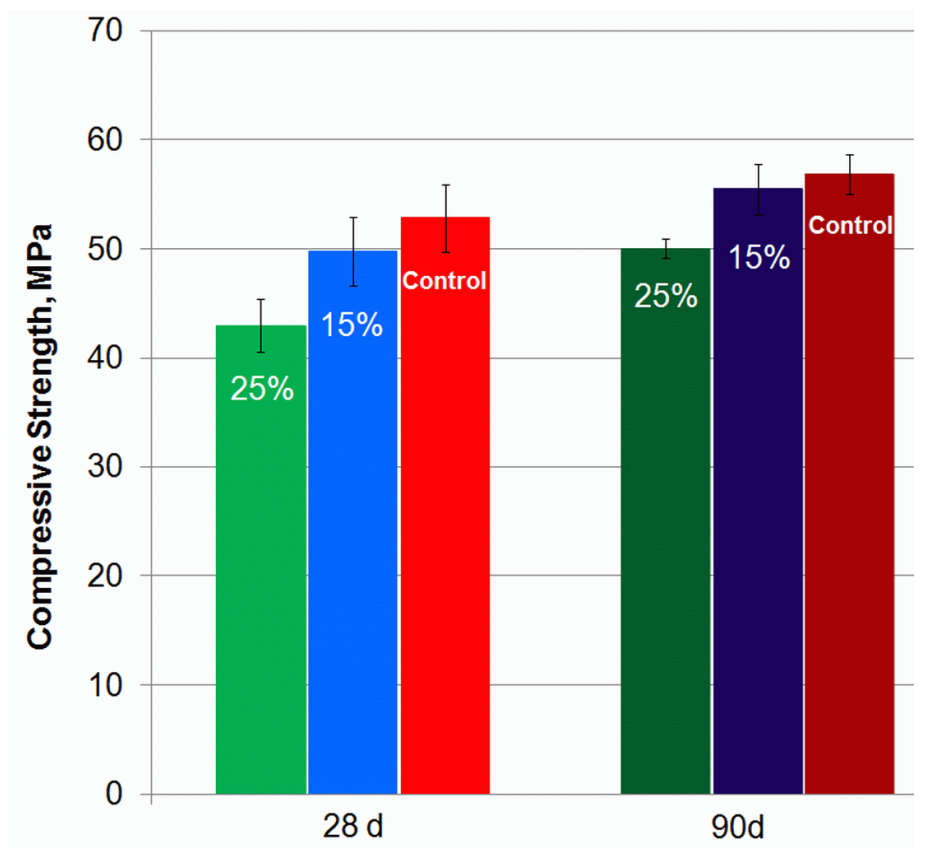

Fig. 3 - Compressive strength of the control mortar, and of the mortars with 15 wt. $\%$ and 25 wt.\% of CSW cured for 28 and 90 days.

The strength activity index (SAI) and strength gain (SG) are plotted in Fig. 4a and 4b, respectively. All the mortars containing CSW presented an SAI higher than 0.75, which indicates that some pozzolanic reactions occurred. Furthermore, the fact that the SAI increased with curing time, and came close to 1 after 90 curing days, indicates that waste activates after relatively long curing periods. The obtained results met the specifications established in UNE EN 196-1, and were higher than $75 \%$ and $85 \%$ in the mortars containing 25 wt.\% of waste cured for 28 and 90 days, respectively. As observed in Fig. 4b, the contribution of the pozzolanic additions to compressive strength became more significant after 90 curing days, especially for that with the most ceramic contents.

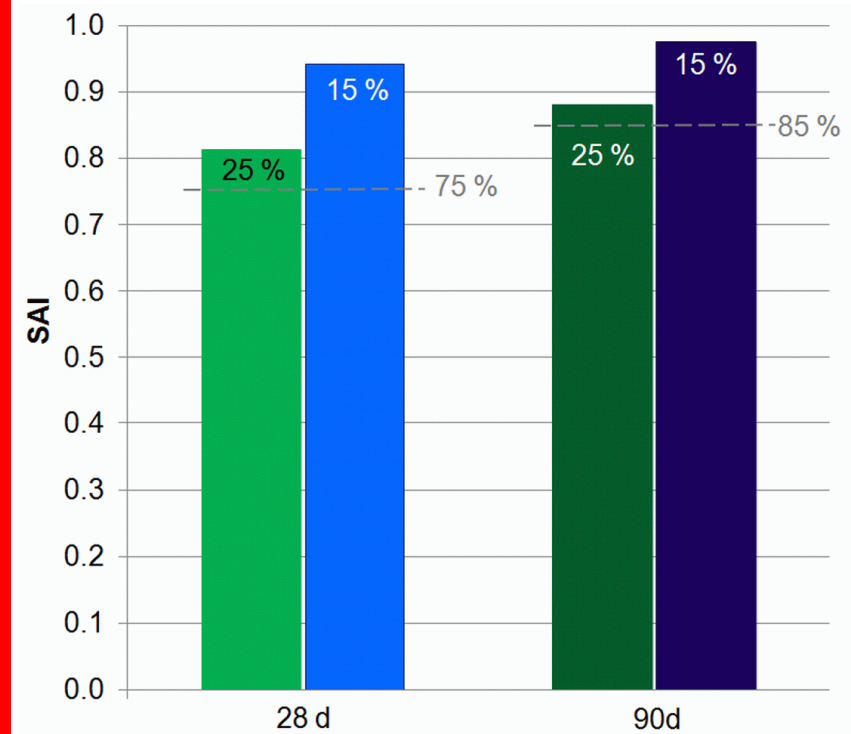

a

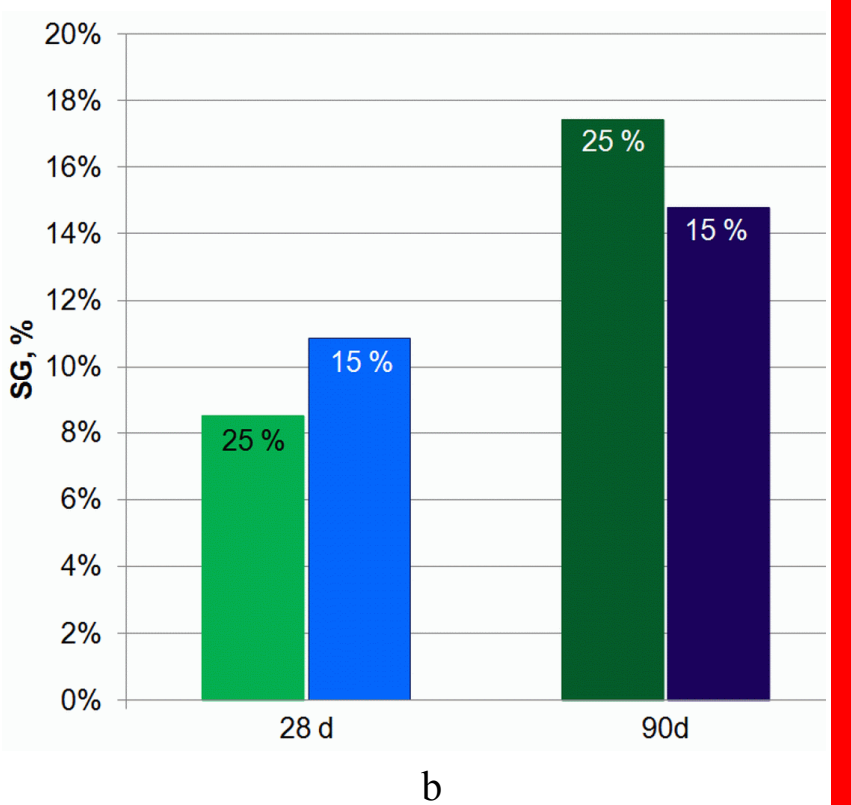

Fig. 4 - Compressive strength of the mortars containing 15 wt. $\%$ and 25 wt. $\% \mathrm{CSW}$, cured at $20^{\circ} \mathrm{C}$ for 28 and 90 days: a) Strength activity index (SAI); b) Strength gain (SG). 
3.2.2. Alkali-activated CSW mortars. Influence of $\mathrm{SiO}_{2}$ and sodium concentration on compressive strength. The compressive strength evolutions of the mortars with increasing $\mathrm{SiO}_{2}$ and $\mathrm{Na}^{+}$contents, cured at $65^{\circ} \mathrm{C}$ for 3 days, are plotted in Fig. 5a. Although all the mortars prepared with a $\mathrm{SiO}_{2} / \mathrm{Na}_{2} \mathrm{O}$ ratio below 1.10 exhibited rapid setting or poor workability, that mixed with 1.82 $\mathrm{mol} / \mathrm{kg}$ of $\mathrm{SiO}_{2}$ and $10.0 \mathrm{~mol} / \mathrm{kg}$ of $\mathrm{Na}^{+}\left(\mathrm{SiO}_{2} / \mathrm{Na}_{2} \mathrm{O}=0.35\right)$ gave an unexpectedly high compressive strength value $(\approx 14 \mathrm{MPa})$. This mortar exhibited poor workability during the mixing process, with the formation of dry particles which were difficult to agglomerate.

The best mechanical properties were presented by the mortars containing the highest silica concentrations $\left(7.28 \mathrm{SiO}_{2} \mathrm{~mol} / \mathrm{kg}\right)$. These mortars were further analyzed by curing them for 7 days at $65^{\circ} \mathrm{C}$. As observed in Fig. $5 \mathrm{~b}$, although the mortars cured for 3 days presented no particular evolution with the $\mathrm{Na}^{+}$concentration, the mechanical properties progressively improved with the sodium content after 7 curing days.

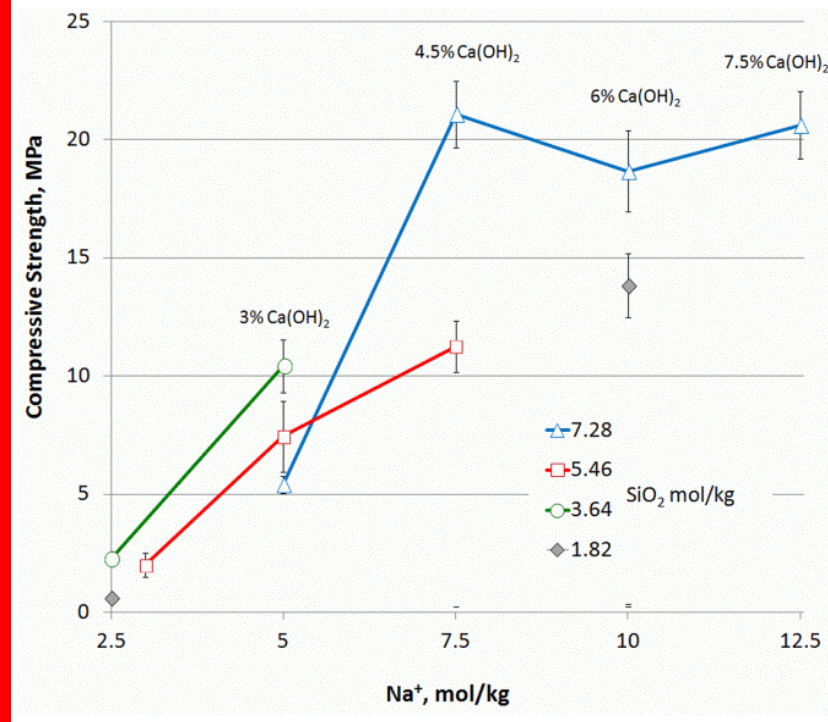

a

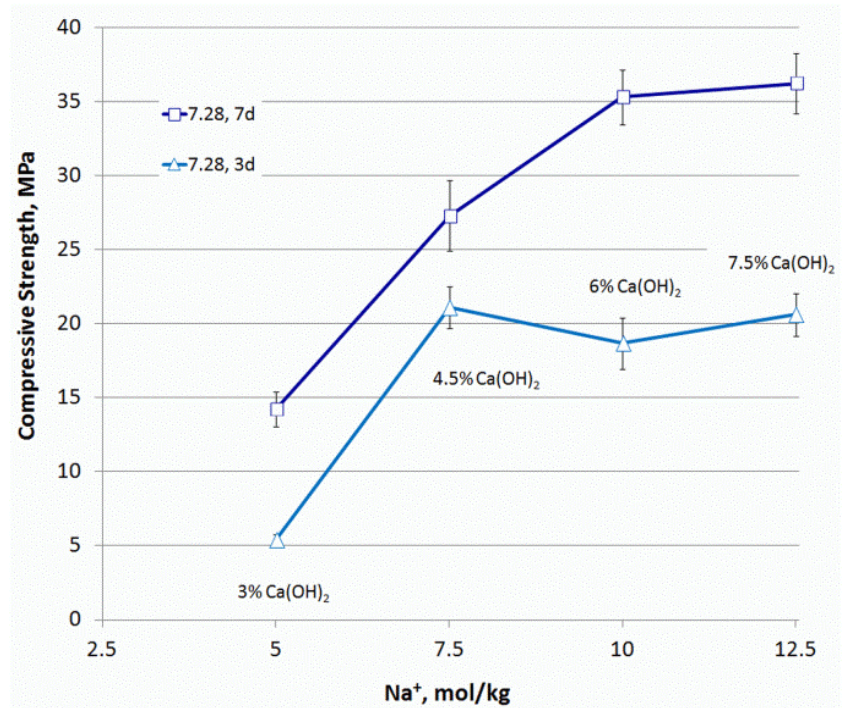

$\mathrm{b}$

Fig. 5 - Compressive strength of the alkali-activated CSW mortars: a) Influence of $\mathrm{SiO}_{2}$ and $\mathrm{Na}^{+}$ concentrations on the mortars cured for 3 days at $65^{\circ} \mathrm{C}$; b) Influence of the $\mathrm{Na}^{+}$concentration on the mortars mixed with $7.28 \mathrm{~mol} / \mathrm{kg}$ of $\mathrm{SiO}_{2}$ cured at $65^{\circ} \mathrm{C}$ for 3 and 7 days.

\subsection{Microstructural analyses.}

3.3.1. Microstructural studies of Portland cement pastes. The thermogravimetric results of the Portland cement pastes and those containing $15 \mathrm{wt} . \%$ and $25 \mathrm{wt} . \%$ of CSW, cured at $20^{\circ} \mathrm{C}$ for 28 and 90 days are plotted in Fig. 6 and 7. While the percentage of fixed lime and water released by the hydrates formed are shown in Fig. $6 \mathrm{a}$ and 6b, respectively, the thermogravimetric curves (DTG) are provided in Fig. 7.

Negative-fixed lime parameter values were mainly obtained. This is attributed to the particle effect created by the ceramic waste, which enhanced the Portland cement hydration reactions, leading to an increase of the peak attributed to portlandite on the thermogravimetric curve $(\sim$ $560^{\circ} \mathrm{C}$ ). The positive value obtained in the pastes with $15 \mathrm{wt} . \% \mathrm{CSW}$ cured for 90 days is attributed to the pozzolanic reaction, where portlandite was consumed by ceramic waste.

As observed in Fig. 6b, the amount of formed hydrates increased with curing time, and was slightly lower in the pastes containing CSW than in the control paste. This was because the pozzolanic reaction of the CSW was kinetically slow and Portland cement hydration predominated. 


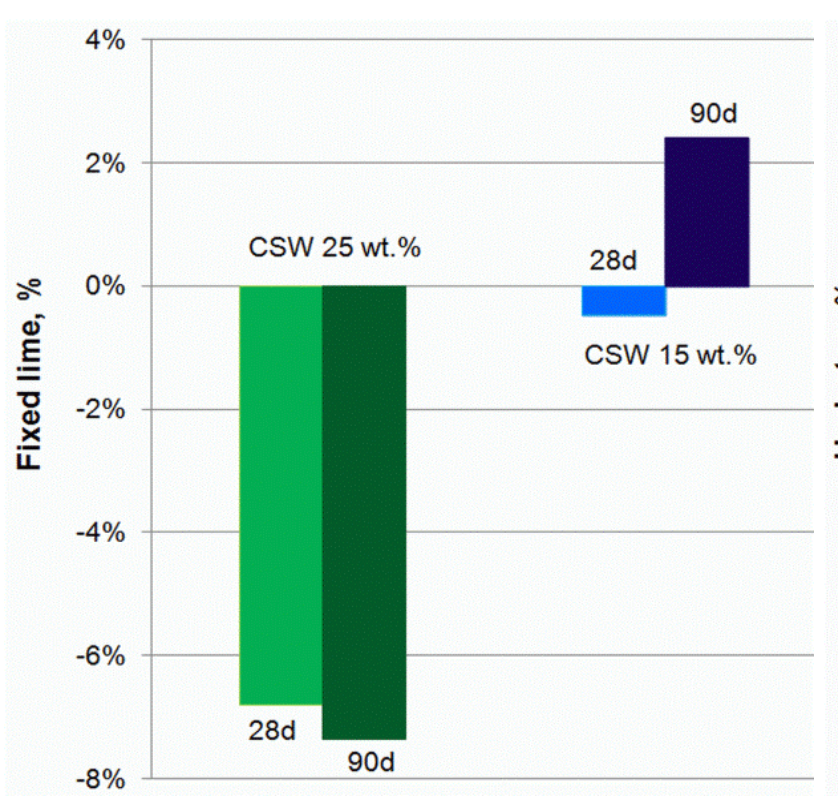

a

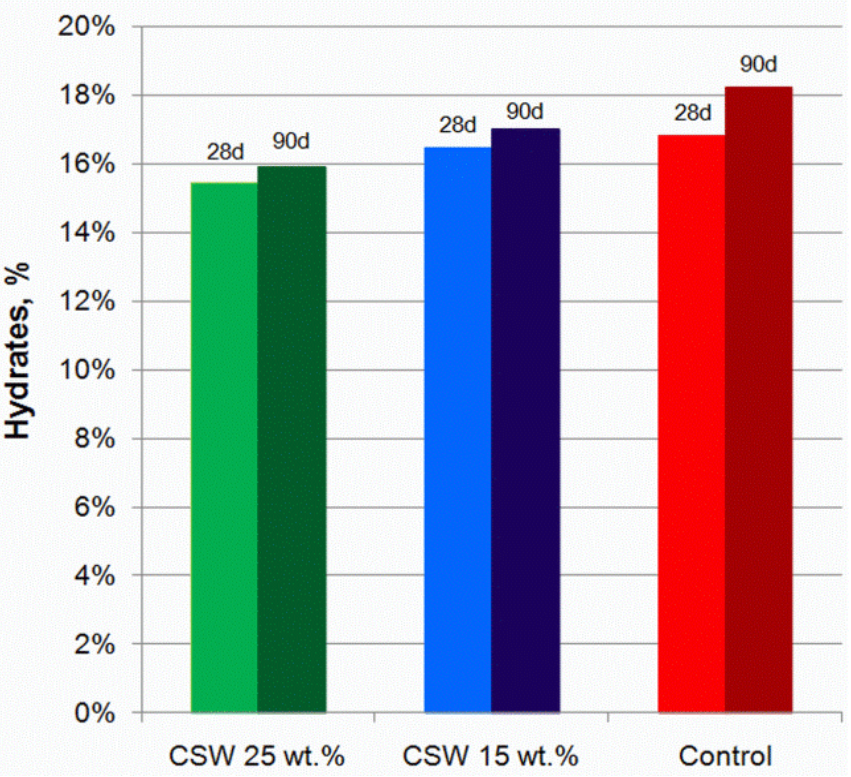

$\mathrm{b}$

Fig. 6 - Thermogravimetric analyses of the control paste and those containing $15 \mathrm{wt} . \%$ and $25 \mathrm{wt} . \%$ of ceramic waste cured at $20^{\circ} \mathrm{C}$ for 28 and 90 days: a) Fixed lime; b) Water mass loss from hydrates.

The thermogravimetric curves of the pastes containing CSW were similar to that of the control paste; Fig. 7. The peaks appearing within the $120-170^{\circ} \mathrm{C}$ range, which became more pronounced with curing time, are attributed to the dehydration of calcium silicate hydrates $(\mathrm{C}-\mathrm{S}-\mathrm{H})$ and ettringite, and the peak centered at $210^{\circ} \mathrm{C}$ corresponds to the dehydration of the calcium aluminate and aluminosilicate hydrates $(\mathrm{C}-\mathrm{A}-\mathrm{H}$ and $\mathrm{C}-\mathrm{A}-\mathrm{S}-\mathrm{H})[7]$. The dehydroxylation of Portlandite $(\mathrm{CH})$ is identified by the mass loss process appearing at $520-580^{\circ} \mathrm{C}$ in the diagram. As observed, the intensity of this peak was the highest for the control paste since there was less Portland cement in the blended mixtures. This was also because part of this mineral phase was consumed by ceramic waste during the pozzolanic reaction.

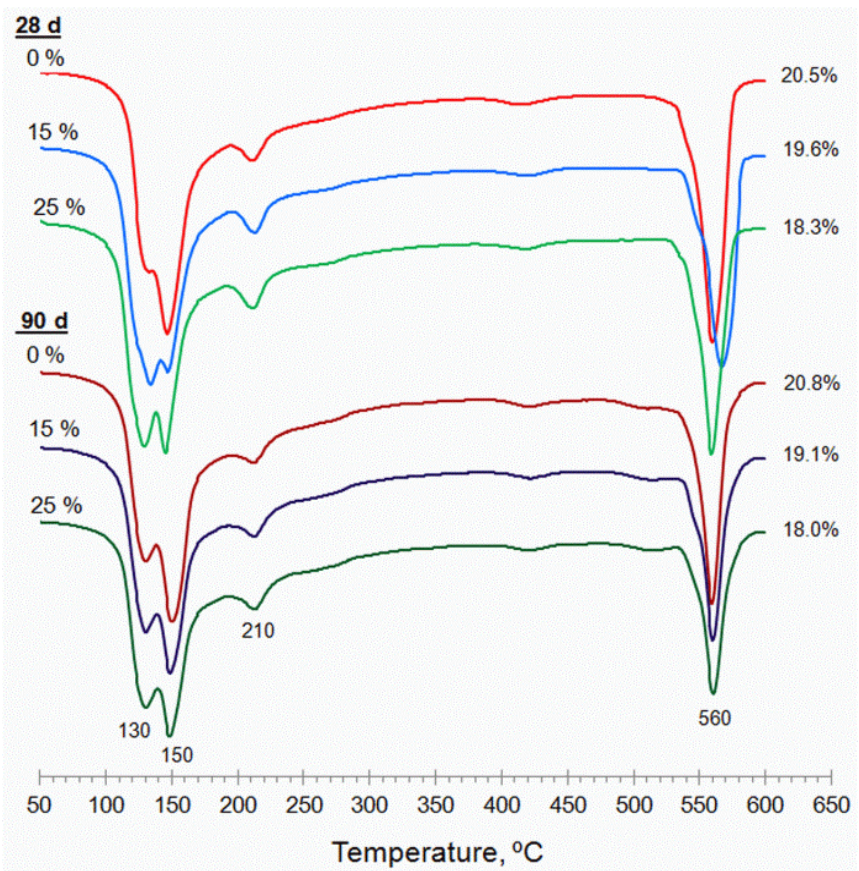

Fig. 7 - Thermogravimetric curves of pastes with 0,15 and 25 wt.\% CSW substitution cured at $20^{\circ} \mathrm{C}$ for 28 and 90 days. 
Fig. 8 presents the microstructure of the Portland cement pastes containing 15 wt. $\%$ and 25 wt. $\%$ of $\mathrm{CSW}$ cured at $20^{\circ} \mathrm{C}$ for 28 days. The presence of ettringite needles, hexagonally stacked portlandite and the amorphous CSH gel formed during the hydration process, previously identified by the TG analyses, is confirmed.

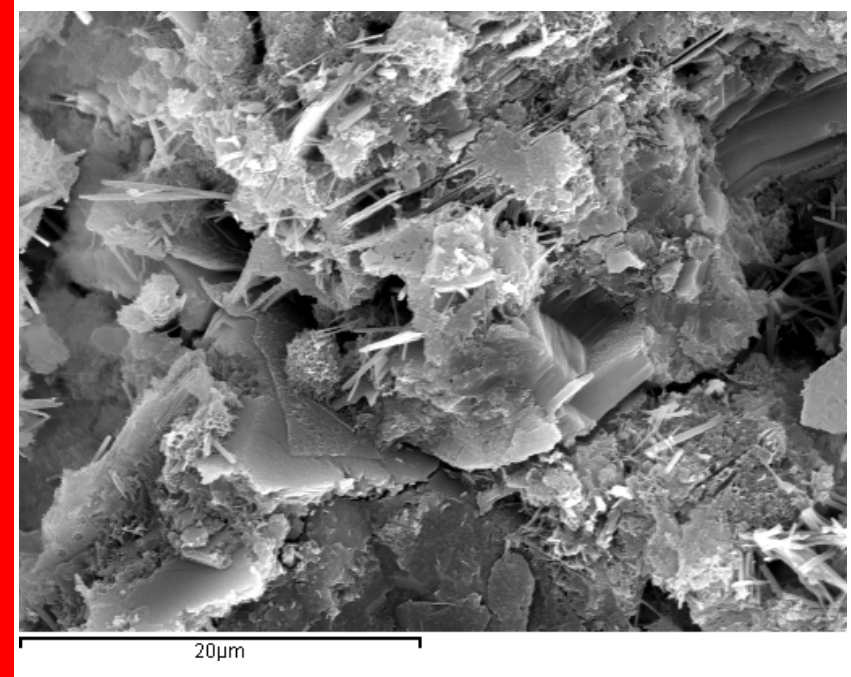

a

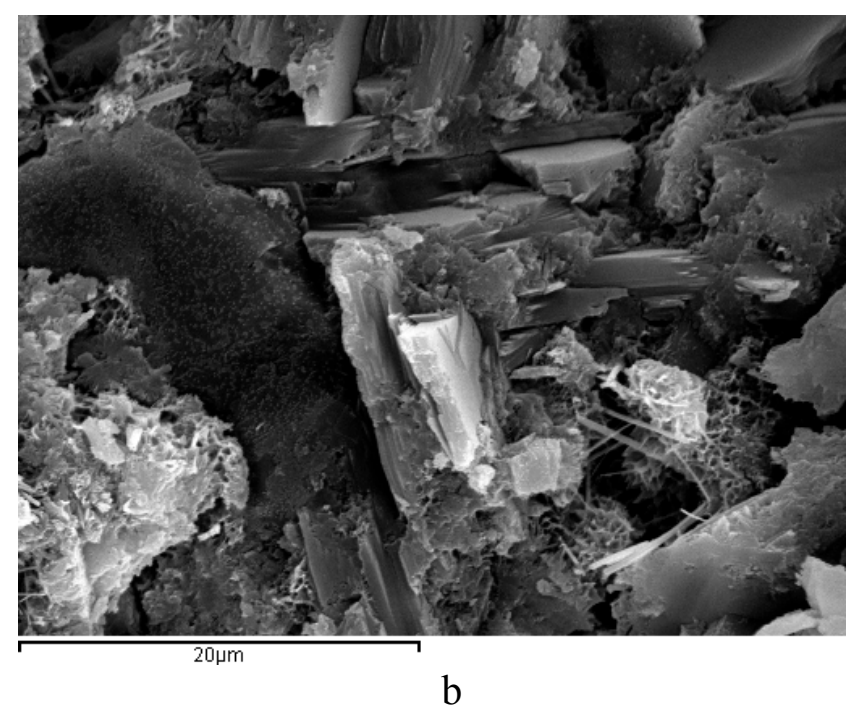

b

Fig. 8 - SEM images of the Portland cement pastes cured at $20^{\circ} \mathrm{C}$ for 28 days: a) 15 wt.\% CSW; b) 25 wt.\% CSW.

3.3.2. Microstructural studies of alkali-activated CSW pastes. Pastes of the mortar mixed with $7.28 \mathrm{~mol} / \mathrm{kg}$ of $\mathrm{SiO}_{2}, 7.5 \mathrm{~mol} / \mathrm{kg}$ of sodium and $4.5 \mathrm{wt} . \%$ of $\mathrm{Ca}(\mathrm{OH})_{2}$, which exhibited the best workability, were analyzed by TG and SEM. For this purpose, pastes were cured at $65^{\circ} \mathrm{C}$ for 7 days. The total weight loss recorded in the thermogravimetric analyses was $9.95 \mathrm{wt} . \%$ and, similarly to previous studies [5,6], in which red clay brick waste and porcelain stoneware were alkali-activated, a single broad band was observed within the $120-150^{\circ} \mathrm{C}$ range, which is attributed to chemically bonded water in the produced gel. As observed in Fig. 9, a dense microstructure originated after the alkali-activation process of CSW.

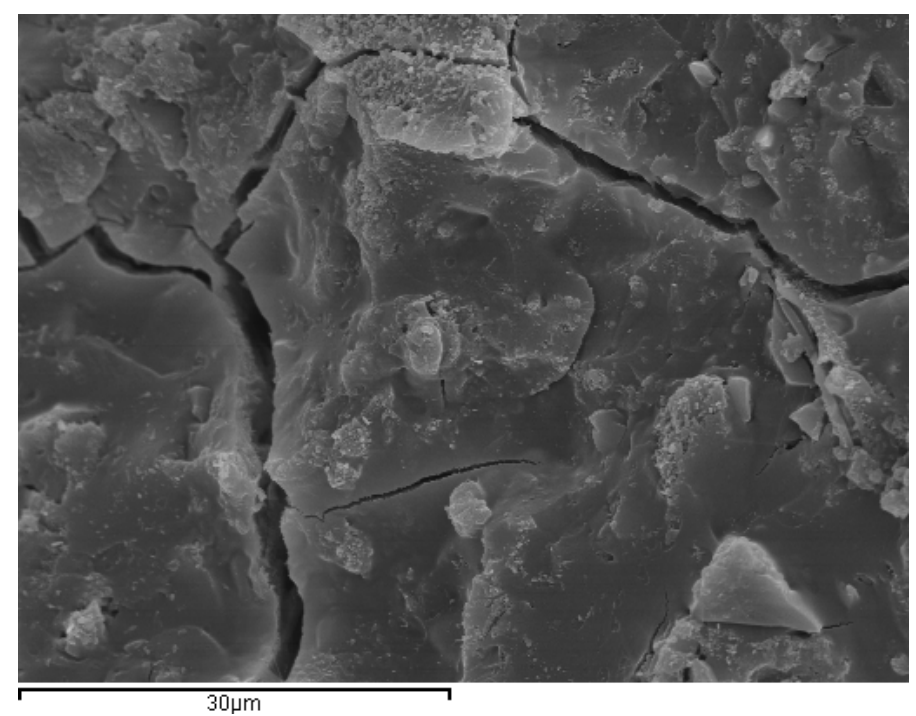

Fig. 9 - SEM image of the CSW alkali-activated paste cured for 7 days at $65^{\circ} \mathrm{C}$. 


\section{Conclusions}

New binders have been successfully developed by the alkali-activation of ceramic sanitary-ware waste and its use as a partial replacement of Portland cement:

- Ceramic waste contains almost 90 wt.\% of $\mathrm{SiO}_{2}$ and $\mathrm{Al}_{2} \mathrm{O}_{3}$, and part of the material is in an amorphous state. These properties make it a good candidate to develop more sustainable binders.

- The reactivity of ceramic waste with the Portlandite originated during Portland cement hydration increased with curing time.

- The mortars containing 15 wt.\% and 25 wt.\% CSW, to substitute Portland cement, satisfy the mechanical strength requirements set out in fly ash regulations, and present an SAI higher than 75\% and $85 \%$ after 28 and 90 curing days, respectively.

- The best compressive strength results of all the alkali-activated CSW mortars are presented by that mixed with the highest $\mathrm{SiO}_{2}$ concentrations, which range from 15 to $36 \mathrm{MPa}$ after 7 curing days at $65^{\circ} \mathrm{C}$, and depend on the sodium concentration in the alkali activator.

\section{Acknowledgments}

The authors are grateful to the Spanish Ministry of Economy and Competitiveness for supporting this study through Project GEOCEDEM BIA 2011-26947 and FEDER funding.

\section{References}

[1] S. Ioannou, L. Reig, K. Paine, K. Quillin, Properties of a ternary calcium sulfoaluminatecalcium sulfate-fly ash cement, Cem. Concr. Res. 56 (2014) 75-83.

[2] A. Halicka, P. Ogrodnik, B. Zegardlo, Using ceramic sanitary ware waste as concrete aggregate, Constr. Build. Mater. 48 (2013) 295-305.

[3] C. Medina, A. Juan, M. Frías, M.I. Sánchez de Rojas, J.M. Morán, M.I. Guerra, Characterization of concrete made with recycled aggregate from ceramic sanitary ware, Mater. Constr. 61, 304 (2011) 533-546.

[4] F. Puertas, I. García-Díaz, A. Barba, M.F. Gazulla, M. Palacios, M.P. Gómez, S. MartínezRamírez, Ceramic wastes as alternative raw materials for Portland cement clinker production, Cem. Concr. Compos. 30, 9 (2008) 798-805.

[5] L. Reig, M.M. Tashima, M.V. Borrachero, J. Monzó, C.R. Cheeseman, J. Payá, Properties and microstructure of alkali-activated red clay brick waste, Constr. Build. Mater. 43 (2013) 98-106.

[6] L. Reig, L. Soriano, M.V. Borrachero, J. Monzó, J. Payá, Influence of the activator concentration and calcium hydroxide addition on the properties of alkali-activated porcelain stoneware, Constr. Build. Mater. 63 (2014) 214-222.

[7] J. Payá, J. Monzó, M.V. Borrachero, S. Velázquez, Evaluation of the pozzolanic activity of fluid catalytic cracking catalyst residue (FC3R). Thermogravimetric analysis studies on FC3R-Portland cement pastes, Cem. Concr. Res. 33 (2003) $603-609$. 